\title{
Human Nek6 is a monomeric mostly globular kinase with an unfolded short $\mathrm{N}$-terminal domain
}

\author{
Gabriela V Meirelles ${ }^{1,2}$, Júlio C Silva', Yuri de A Mendonça ${ }^{1,2,3}$, Carlos HI Ramos ${ }^{2,3}$, Iris L Torriani ${ }^{4,5}$, Jörg Kobarg ${ }^{1,2^{*}}$
}

\begin{abstract}
Background: The NIMA-related kinases (Neks) are widespread among eukaryotes. In mammalians they represent an evolutionarily conserved family of 11 serine/threonine kinases, with $40-45 \%$ amino acid sequence identity to the Aspergillus nidulans mitotic regulator NIMA within their catalytic domains. Neks have cell cycle-related functions and were recently described as related to pathologies, particularly cancer, consisting in potential chemotherapeutic targets. Human Nek6, -7 and -9 are involved in the control of mitotic spindle formation, acting together in a mitotic kinase cascade, but their mechanism of regulation remain elusive.

Results: In this study we performed a biophysical and structural characterization of human Nek6 with the aim of obtaining its low resolution and homology models. SAXS experiments showed that hNek6 is a monomer of a mostly globular, though slightly elongated shape. Comparative molecular modeling together with disorder prediction analysis also revealed a flexible disordered $\mathrm{N}$-terminal domain for hNek6, which we found to be important to mediate interactions with diverse partners. SEC-MALS experiments showed that hNek6 conformation is dependent on its activation/phosphorylation status, a higher phosphorylation degree corresponding to a bigger Stokes radius. Circular dichroism spectroscopy confirmed our in silico predictions of secondary structure content and thermal stability shift assays revealed a slightly higher stability of wild-type hNek6 compared to the activation loop mutant hNek6(S206A).

Conclusions: Our data present the first low resolution 3D structure of hNek6 protein in solution. SAXS, comparative modeling and SEC-MALS analysis revealed that hNek6 is a monomeric kinase of slightly elongated shape and a short unfolded N-terminal domain.
\end{abstract}

\section{Background}

Mitotic progression and assembly of the bipolar mitotic spindle are regulated by several serine/threonine protein kinases, including members of the cyclin-dependent kinase (Cdk), Polo-like kinase (Plk), Aurora, and NIMA-related kinase (Nek) families [1-4]. The founding member of Nek family, the NIMA kinase of Aspergillus nidulans, contributes to multiple aspects of mitotic progression including the timing of mitotic entry, chromatin condensation, spindle organization and cytokinesis. Mammals contain a large family of eleven Neks, the catalytic domain of which is evolutionarily related to that of NIMA [4]. Nek2 has a central role in centrosome maturation and disjunction [5], whereas Nek1 and Nek8 have been proposed to contribute

\footnotetext{
* Correspondence: jorg.kobarg@|nbio.org.br

'Laboratório Nacional de Biociências, Centro Nacional de Pesquisa em Energia e Materiais, Campinas, SP, Brazil

Full list of author information is available at the end of the article
}

to ciliary function [6,7]. Besides Nek2, Nek1, -6, -7 and -9 were also described to participate in centrosomal regulation [7-11]. Nek6, Nek7 [9] and Nek9 [12] are involved in the control of mitotic spindle formation, acting together in a mitotic kinase cascade, with Nek9 being upstream of Nek6 and Nek7 [13]. Nek kinases are also described as related to pathologies, particularly cancer, presenting thereby interesting potential chemotherapeutic targets [14-20]. Recently, hNek6 was described to have its transcript, protein, and/or kinase activity levels highly elevated in a number of tumors and human cancer cell lines, indicating an important role for hNek6 in tumorigenesis [21-24].

Structurally, Neks in general are characterized by having a conserved $\mathrm{N}$-terminal catalytic domain, followed by a nonconserved $\mathrm{C}$-terminal regulatory domain that varies in size and structure. However, Nek6 and Nek7 are significant exceptions to this, in that they are the 
smallest of the kinases and consist only of a catalytic domain with a relatively short $\mathrm{N}$-terminal extension [4]. Although they share significant similarity with each other, being $\sim 86 \%$ identical within their catalytic domains, the $\mathrm{N}$-terminal extensions are not conserved, and it has been suggested that they may play a role in differential regulation of the kinases [25].

The mechanisms of regulation of hNek6, -7, and -9 kinases are currently unknown, and elucidating this pathway would provide relevant knowledge on early mitotic events as well as new hints for drug design and cancer therapy. However, hNek2 and hNek7 are the only NIMA-related kinases for which structures have been reported [26-28]. In this context, we present here the first low resolution three-dimensional structure of hNek6 protein in solution. SAXS experiments, together with SEC-MALS and comparative molecular modeling revealed a monomeric mostly globular, though slightly elongated conformation for hNek6, with a flexible disordered N-terminal domain.

\section{Results and Discussion}

Human Nek6 is predicted to be phosphorylated at various sites and has an unfolded short $\mathrm{N}$-terminal domain

Human Nek6 amino acid sequence was analyzed considering its secondary structure, disordered regions, conserved motifs and putative phosphorylation sites by upstream kinases, resulting in a linear representation of its main structure predictions (Figure 1A). These analyses were also performed for hNek7, for which the crystallographic structure was recently determined [28], in order to validate our results (Figure 1B).

Our consensus of secondary structure was scored by the number of times (one to five times) the predicted secondary structure element ( $\alpha$-helices, $\beta$-strands or coils) scored positive from five predictions using different databases: PredictProtein/Prof [29], PSIPRED [30], SSpro [31], SOPMA [32] and GOR4 [33]. In summary, the secondary structure analysis suggested that hNek6 was composed of approximately $34 \% \alpha$-helices, $12 \% \beta$ strands and $54 \%$ coils. Our hNek7 consensus of predicted secondary structure is $80 \%$ identical to the author-approved secondary structure in PDB (2WQM) (Figure 1B).

In the case of the disordered regions predictions, our consensus was obtained following the same criteria as for the secondary structure predictions, except that we used here nine different databases: FoldIndex [34], GlobPlot Russell/Linding [35], PONDR VL-XT [36], DISpro [37], IUPred [38], DisEMBL Hot-loops, DisEMBL Remark-465, DisEMBL Loops/coils [39], and VSL2B [40]. From this analysis, we were able to identify a short high scored segment of disorder covering the majority of hNek6 N-terminal extension before its catalytic domain, which we are calling here the regulatory domain. This characteristic is also present in our hNek7 consensus of disorder predictions and in its crystal structure [28], where amino acids 1-19 are missing residues (due to a flexible region) and amino acids 20-23 are coils. Notably, we found that hNek6 unfolded short $\mathrm{N}$-terminal region is important to mediate interactions with diverse partners [41] and, since hNek6 and hNek7 are similar in their catalytic domain sequences $(\sim 86 \%$ identity), but different in their $\mathrm{N}$-terminal extensions ( 20\% identity) (Figure 1C), it is possible that both proteins depend on their disordered $\mathrm{N}$-terminal domain to regulate the interactions with specific/different partners.

For phosphorylation analysis, NetPhosK [42] and NetPhos [43] databases were used to predict phosphorylation sites (Table 1), and together with in vitro and in vivo phosphorylation data [13], they were used to assign tyrosine, threonine and serine residues as putative phosphorylation sites for hNek6 and hNek7 (Figure 1). This analysis shows a variety of high score phosphorylation predictions for hNek6. Interestingly, there are four predicted sites localized in hNek6 N-terminal domain (serine residues 13,14, 37 and 41), and one of them $\left(\mathrm{Ser}^{37}\right)$ also described to be phosphorylated in vivo [13], suggesting that this is an important phosphorylationregulated region.

\section{Secondary structure analysis}

The secondary structure content of hNek6 was analyzed by Circular Dichroism (CD) spectroscopy. Figure 2 shows the CD spectra of recombinant wild-type hNek6 fused to a $6 \mathrm{xHis}$-tag recorded at $4{ }^{\circ} \mathrm{C}$. Purified protein presents negative ellipticity in the far-UV, with minima at $208\left(-15567 \mathrm{deg} \mathrm{cm}^{2} \mathrm{dmol}^{-1}\right)$ and $222 \mathrm{~nm}(-12053 \mathrm{deg}$ $\left.\mathrm{cm}^{2} \mathrm{dmol}^{-1}\right)$. This spectrum is typical of many globular proteins [44] and suggests a high content of $\alpha$-helices, since this secondary structure is characterized by minima around 208 and $222 \mathrm{~nm}$. Deconvolution of the CD spectrum using the CDNN software [45] indicated approximately $41.7 \%$ of $\alpha$-helices, $13.2 \%$ of $\beta$-strands, $15.7 \%$ of beta-turns and $25.8 \%$ of random coils. Deconvolution using another software, K2d [46], indicated a similar amount of secondary structure elements: approximately $41 \%$ of $\alpha$-helices, $17 \%$ of $\beta$-strands and $42 \%$ of coils. We also estimated the quantity of $\alpha$-helix structure by the evaluation of the CD spectrum signal at $222 \mathrm{~nm}$, according to Corrêa and Ramos, 2009 [47], resulting in 38.6\% of $\alpha$-helices. Compared to our predictions, wild-type hNek6 showed a very similar content of $\alpha$-helices $(\sim 34 \%), \beta$ strands (12\%) and coils (54\%). In conclusion, both the in silico prediction and the experimentally derived data 


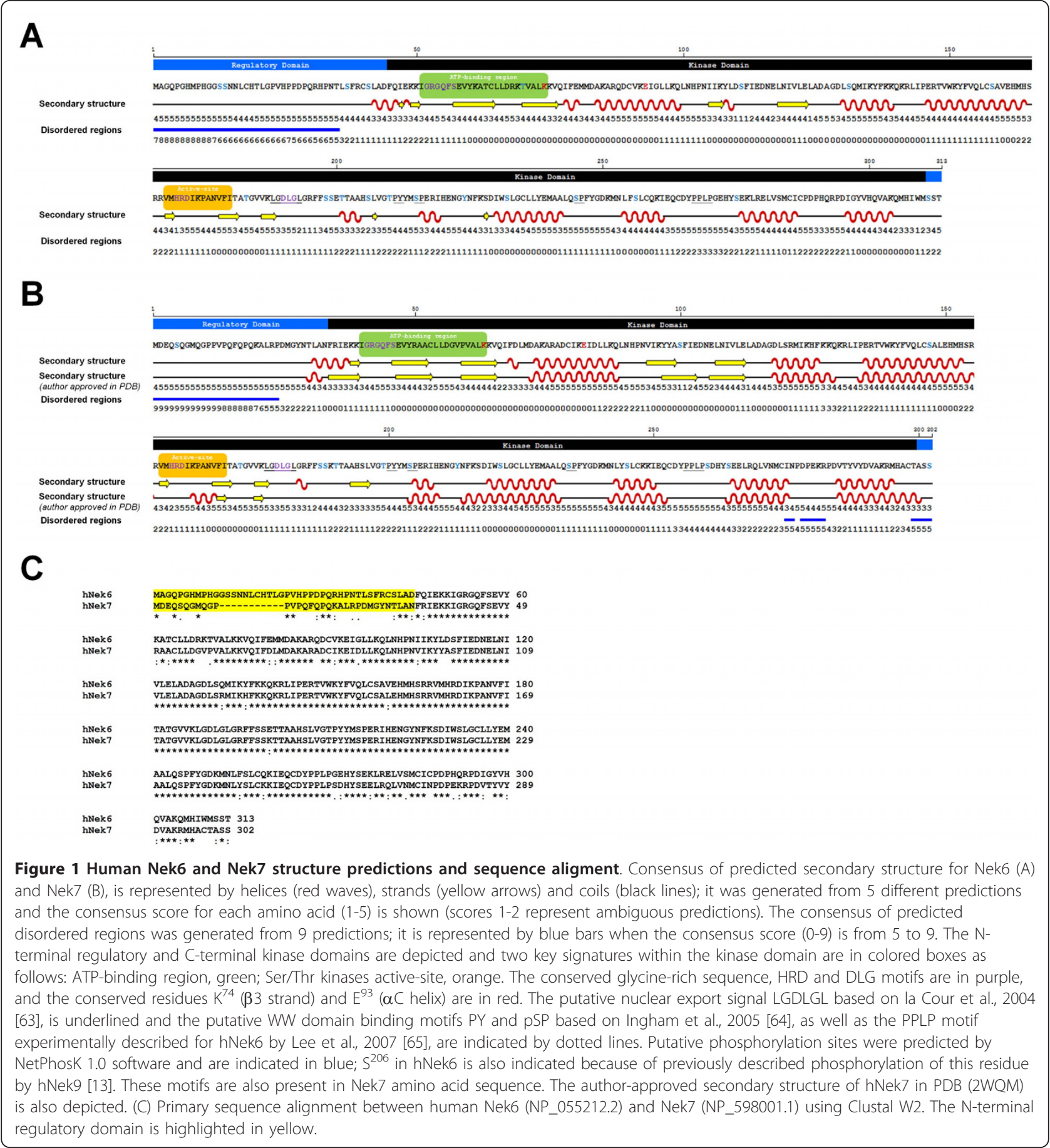

are in reasonable agreement, since they demonstrate an expected high $\alpha$-helical content for hNek6.

\section{Comparative molecular modeling of human Nek6}

The absence of a three-dimensional structure of hNek6 and the increasing interest in studying Nek proteins within the context of drug design strategies prompted us to construct a homology model for the aforementioned protein.
Here, we are interested in the activation loop mutant hNek6(S206A). The activation loop is a centrally located loop, typically 20-30 residues in length, that provides a platform for the peptide substrate. Activation of most protein kinases usually requires phosphorylation of a residue in this loop, which leads to a rearrangement of the loop and increase in enzymatic activity [48]. In hNek6, S206 is an important residue, which phosphorylation leads to an 
Table 1 Prediction of putative phosphorylation sites in human Nek6

\begin{tabular}{|c|c|c|}
\hline Residue $^{a}$ & Putative Upstream Kinase ${ }^{\mathbf{b}}$ & Predictor (Score) \\
\hline$S^{13}$ & PKA & NetPhosK (0.63) \\
\hline$S^{14}$ & PKA & NetPhosK (0.52) \\
\hline$S^{14}$ & $\mathrm{Cdc} 2$ & NetPhosK (0.53) \\
\hline$S^{37}$ & PKC & NetPhosK (0.82) \\
\hline$S^{41}$ & PKC & NetPhosK (0.56)/NetPhos (0.72) \\
\hline$S^{41}$ & PKA & NetPhosK (0.65)/NetPhos (0.72) \\
\hline$T^{70}$ & PKC & NetPhosK (0.79) \\
\hline$S^{111}$ & CKII & NetPhosK (0.64) \\
\hline$S^{131}$ & DNAPK & NetPhosK (0.62) \\
\hline$S^{131}$ & ATM & NetPhosK (0.68) \\
\hline$S^{158}$ & CKII & NetPhosK (0.53) \\
\hline$S^{158}$ & $\mathrm{Cdc} 2$ & NetPhosK (0.51) \\
\hline$T^{183}$ & PKC & NetPhosK (0.65) \\
\hline$S^{198}$ & PKA & NetPhosK (0.56)/NetPhos (0.79) \\
\hline$S^{198}$ & $\mathrm{Cdc} 2$ & NetPhosK (0.50)/NetPhos (0.79) \\
\hline$S^{199}$ & CKII & NetPhosK (0.50) \\
\hline$S^{199}$ & Cdc2 & NetPhosK (0.55) \\
\hline$T^{201}$ & PKC & NetPhosK (0.73) \\
\hline$S^{206}$ & $\mathrm{CKI}$ & NetPhosK (0.53)/NetPhos (0.99) \\
\hline$T^{210}$ & GSK3 & NetPhosK (0.51) \\
\hline$T^{210}$ & CDK5 & NetPhosK (0.55) \\
\hline$S^{215}$ & GSK3 & NetPhosK (0.50)/NetPhos (0.99) \\
\hline$S^{215}$ & Cdk5 & NetPhosK (0.59)/NetPhos (0.99) \\
\hline$Y^{224}$ & EGFR & NetPhosK (0.55)/NetPhos (0.72) \\
\hline$S^{232}$ & PKA & NetPhosK (0.67) \\
\hline$S^{245}$ & p38MAPK & NetPhosK (0.50) \\
\hline$S^{245}$ & Cdk5 & NetPhosK (0.55) \\
\hline$S^{256}$ & $\mathrm{CKI}$ & NetPhosK (0.54) \\
\hline $\mathrm{S}^{256}$ & PKC & NetPhosK (0.50) \\
\hline$S^{275}$ & CKII & NetPhosK (0.52) \\
\hline$S^{311}$ & PKC & NetPhosK (0.66) \\
\hline
\end{tabular}

${ }^{a}$ Putative phosphorylated residues predicted with the highest scores by NetPhosK, which may additionally be predicted by NetPhos server.

${ }^{\mathrm{b}}$ Kinases as predicted by NetPhosK to phosphorylate the corresponded residue in hNek6 sequence [Protein Kinase A, C or G (PKA, PKC and PKG); Cell division cycle 2 (Cdc2); Casein Kinase I or II (CKI and CKII); DNA-dependent Protein Kinase (DNAPK); Ataxia Telangiectasia Mutated (ATM); Ciclindependent kinase 5 (Cdk5); Glycogen synthase kinase 3 (GSK3); Epidermal Growth Factor Receptor (EGFR); Mitogen-Activated Protein Kinase p38 (p38MAPK)].

increase in the activation status of the kinase [13,41]. The activation loop has the capacity to undergo large conformational changes when the kinase switches between inactive and active states, adopting distinct conformations in different kinases when they are inactive (unphosphorylated activation loop), a fact that has recently been exploited to great medical benefit [49] and which makes our hNek6 mutant an interesting target to be studied.

To obtain a homology model of the hNek6 protein, the crystallographic structure of hNek7, available in the Protein Data Bank (PDB: 2WQM) [28], was used as a

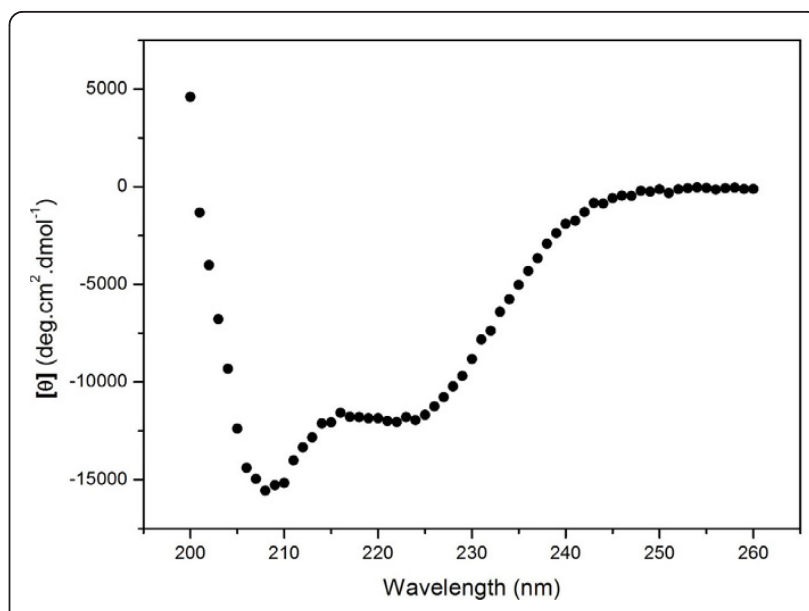

Figure 2 Far-UV Circular Dichroism spectra of recombinant hNek6wt fused to a $\mathbf{6 x H i s}$ tag. Residual molar ellipticity was measured from 200 to $260 \mathrm{~nm}$ at a protein concentration of $5.8 \mu \mathrm{M}$, in $50 \mathrm{mM}$ Phosphate buffer, $\mathrm{pH}$ 7,5 with $300 \mathrm{mM} \mathrm{NaCl}$ at $4^{\circ} \mathrm{C}$ using a Jasco J-810 spectropolarimeter.

template. Both proteins share about $77 \%$ identity in primary sequence alignment, being $\sim 86 \%$ identical in their catalytic domain sequences (Figure $1 C$ ). Several homology/comparative modeling tools were used as described in the "Methods" section of this article. In order to choose the best predicted model, stereochemistry quality analyses were done to check for $\phi$ and $\psi$ torsion angles using the Ramachandran plots. A comparison of the results indicated that the model generated by SWISSMODEL [50] is more acceptable than those generated by the other programs (more amino acids in the most favourable regions and less in the disallowed regions). The SWISS-MODEL homology model is shown in Figure 3. The Ramachandran plot (Additional file 1, Figure S1A) showed $86.6 \%$ residues in the most favourable regions, $12.1 \%$ in additional allowed regions, $0.8 \%$ in generously allowed regions and $0.4 \%$ (only 1 amino acid) in a disallowed region. As compared to the 2WQM template, these values were $90.8 \%, 8.8 \%, 0.4 \%$ and $0.0 \%$, respectively. It is important to keep in mind that the template has relatively long regions (one of them consists of 18 amino acids) where the phases could not be solved by X-ray crystallography. Consequently, the homology modeling may not be so accurate in these regions, although the high identity of the target-template sequences makes the whole model plausible. The results revealed that the majority of the amino acids are in a $\phi-\psi$ distribution consistent with right handed $\alpha$-helix and reliable to be a good quality model (Additional file 1, Figure S1A). More details of the validation of the predicted structure results and its quality assessment using PROSA [51,52] are displayed in the Additional Material section (Additional file 1, Figure S1B and S1C). No abnormalities were observed 


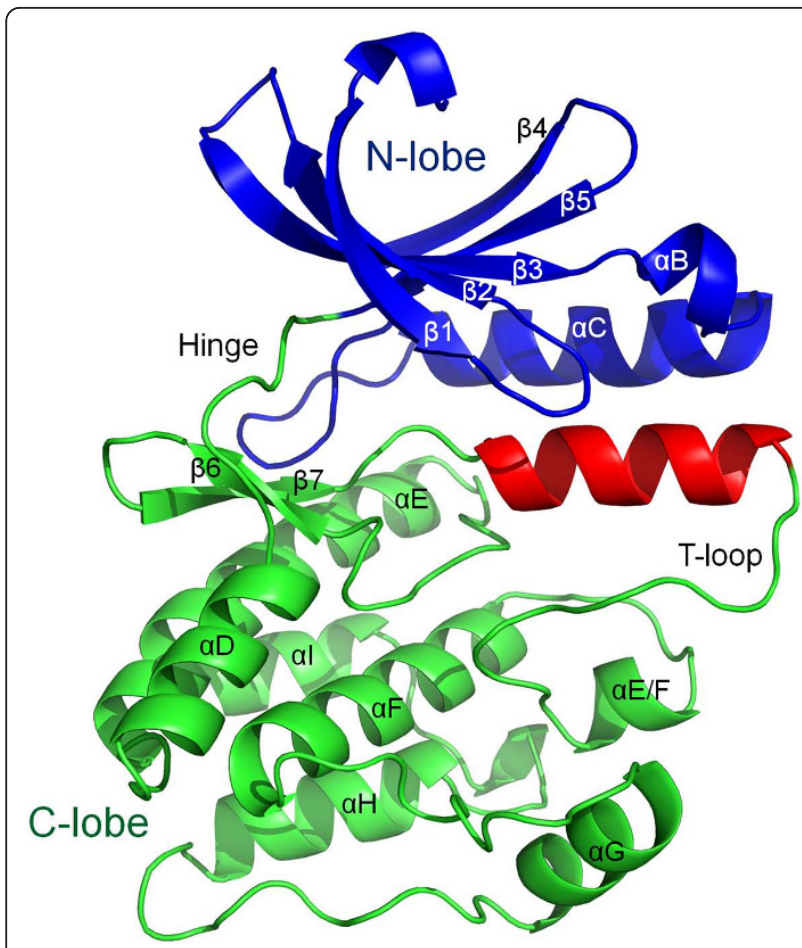

Figure 3 Comparative molecular modeling of hNek6(S206A) based on hNek7 crystal structure. Resulting homology model obtained using the structure deposited in the protein data bank under the code $2 \mathrm{WQM}$. The $\mathrm{N}$ and $\mathrm{C}$ lobes are colored blue and green, respectively, and the predicted $\alpha$-helix following the conserved DLG motif is shown in red. The hinge region and the activation loop (T-loop) are depicted.

in the validation process, which indicated a good model for the protein.

Our hNek6(S206A) model generated by SWISSMODEL [50] shows a short region of $\alpha$-helix composed of twelve residues $\left(\mathrm{G}^{192}\right.$ LGRFFSSETTA $\left.{ }^{203}\right)$ following the conserved DLG motif, with high score (Figure 3). A helical structure following the DFG/DLG motif is also present in hNek2(T175A) structures (PDB: 2JAV, 2W5H and 2W5B) $[26,27]$ and in other kinase families, such as inactive forms of both the EGFR kinase [53] and Src/ Hck [54]. Therefore, although the activation loop is missing in the electron density map of hNek7, a short helical structure is possibly present in hNek6(S206A), which was predicted in the model generated by SWISSMODEL [50].

\section{Human Nek6 is a monomeric mostly globular, though slightly elongated protein in solution, as revealed by SAXS}

To study hNek6 molecular structure, in addition to our homology modeling, we also performed SAXS (Small Angle X-ray Scattering) experiments for the recombi-

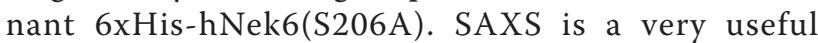

technique for the determination of overall size, shape and oligomerization status of the macromolecules in solution [55-58]. Figure 4A shows the corrected and normalized experimental scattering curve and theoretical fitting of data by using the program GNOM [59]. The Guinier region providing an $R_{\mathrm{g}}$ value of $32.0 \pm 1.0 \AA$ is shown in the inset. The $p(\mathrm{r})$ function resulting from these calculations is shown in Figure 4B, with an inset showing the Kratky representation of the intensity curve. The Kratky plot indicates a slightly globular conformation for $6 x \mathrm{His}-\mathrm{hNek6}(\mathrm{S} 206 \mathrm{~A})$ in solution, although, as expected, the same plot also indicated the presence of flexible regions in the structure, possibly the $\mathrm{N}$-terminal region and the activation loop. The $p(r)$ function shows that the protein conformation is slightly elongated. The maximum dimension $\left(D_{\max }\right)$ value obtained was approximately $110 \AA$ and the $R_{\mathrm{g}}$ value calculated from the $p(\mathrm{r})$ function was $32.4 \pm 0.8 \AA$, in close agreement with that calculated from the Guinier approximation. Using BSA as a standard sample, the molecular mass of 6xHis-hNek6(S206A) estimated from the SAXS data was $\sim 42 \mathrm{kDa}$. This value indicates that the protein is a monomer in solution, since the theoretically calculated molecular mass of the monomer was $\sim 38 \mathrm{kDa}$ (calculated from the amino acid sequence using ProtParam tool [60]). The molecular mass and consequently the monomeric nature were also confirmed by analytical size-exclusion chromatography coupled to multi-angle light scattering (SEC-MALS).

The low-resolution models obtained from the SAXS data by the combination of $a b$ initio calculation and rigid body modeling methods are presented in Figure 5 . The calculated homology model of the mutant hNek6 (S206A) was used in the rigid body calculation. We displayed two typical models of the set of results (Figure $5 \mathrm{~A}$ and $5 \mathrm{~B}$ ) and a superposition of all 10 models (Figure $5 \mathrm{C}$ ) obtained in different and independent runs of the program BUNCH [61]. In spite of the flexibility of the $\mathrm{N}$-terminal region, the NSD values of the pairwise comparison of the models obtained ranged from 0.96 to 1.20 , which shows the stability of the independent calculations. In order to further compare the resulting models with the information contained in the SAXS curve, we also calculated one average molecular envelope of the 10 models (Figure 5D) and compared with the filtered average models obtained from the two sets of 10 purely $a b$ initio model calculations (Figure 5E and 5F).

\section{Analytical size-exclusion chromatography reveals} variations in human Nek6 conformation dependent on its phosphorylation status

Analytical Size-Exclusion Chromatography (SEC) was performed for five variants of recombinant hNek6 fused to a $6 \mathrm{xHis}$ tag: wild-type hNek6 (6xHis-hNek6wt), 


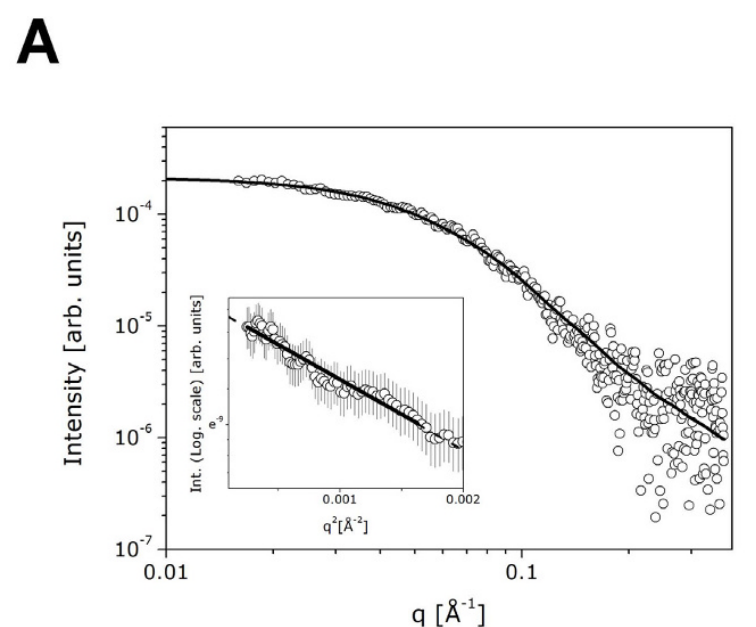

\section{B}

Figure 4 Small Angle X-Ray Scattering (SAXS) of recombinant hNek6(S206A). (A) Experimental SAXS curve from hNek6(S206A) (open circles) and the theoretical fitting (solid line) calculated using the program GNOM. Inset: Guinier region and linear fit. (B) Pair distance distribution function $p(r)$. Inset: Kratky plot $\left(q^{2} I(q)\right.$ vs. q) of the intensity curve.

activation loop mutant hNek6(S206A) (6xHis-hNek6 (S206A), kinase domain of wild-type hNek6 (6xHishNek6( $\Delta 1-44))$, and dephosphorylated wild-type and mutant hNek6 (6xHis-hNek6wtD and 6xHis-hNek6 (S206A)D). Interestingly, the dephosphorylated wild-type and mutant proteins, which were co-expressed with lambda phosphatase, were eluted at equal elution volumes (Figure 6A), showing the same Stokes radius of $\sim 2.1 \mathrm{~nm}$, while the more phosphorylated wild-type hNek6 showed a larger radius of $\sim 2.6 \mathrm{~nm}$ and the partially phosphorylated mutant hNek6(S206A) showed an intermediate radius of $\sim 2.4 \mathrm{~nm}$ (Figure 6B, Table 2). As expected, $6 \mathrm{xHis}-\mathrm{hNek} 6(\Delta 1-44)$ showed the smallest radius of $\sim 1.8 \mathrm{~nm}$. Wild-type hNek6 elution curve also showed a smaller peak corresponding to a population of higher molecular weight, possibly due to aggregates. It is interesting to compare the Stokes radius estimated by SEC for 6xHis-hNek6(S206A) $(\sim 2.4 \mathrm{~nm})$ with the radius of gyration determined by SAXS $(\sim 3.2 \mathrm{~nm})$. The resulting ratio $R_{\mathrm{g}} / R_{\mathrm{s}}$ for this protein is $\sim 1.3$ and, as $R_{\mathrm{g}} / R_{\mathrm{s}}$ ratios are reported to vary from 0.78 for homogeneous spheres, up to values nearing 2 for extended coils and prolate ellipsoids [62]. This reinforces our results that hNek6 has a slightly elongated conformation, with a flexible unfolded N-terminal domain contributing to this shape.

SEC was also coupled to MALS (Multi-Angle Light Scattering), which is an useful technique to measure the weight average molecular masses $\left(M_{\mathrm{w}}\right)$ of the eluted proteins, as described in the Methods section. As expected, wild-type and mutant hNek6, dephosphorylated or not, showed a $M_{\mathrm{w}}$ of $\sim 38 \mathrm{kDa}$, while the kinase domain showed a $M_{\mathrm{w}}$ of $\sim 33 \mathrm{kDa}$ (Table 3, Additional file 1, Figure S2). This corroborates our experimental data from SAXS for 6xHis-hNek6(S206A) and the theoretically calculated molecular masses for all hNek6 variants, showing that hNek6 is a monomer in solution.

These results suggest that, although having the same molecular mass of $\sim 38 \mathrm{kDa}$, wild-type hNek6 is purified from bacteria more phosphorylated than its mutant variant, mainly because of their different activation/autophosphorylation status, as described by Meirelles et al. [41], and these different phosphorylation degrees may cause changes in protein conformation and compactness, resulting in changes in their Stokes radii. This was better visualized for both proteins when dephosphorylated by lambda phosphatase, which promoted smaller radii and, possibly, more compact or less hydrated conformations. It seems that an increase in phosphorylation induces a structural change that increases the apparent size or shape of hNek6. In fact, in most kinases, the activation loop is phosphorylated when the kinase is active, which stabilizes it in an open and extended conformation that is permissive for substrate binding [49]. This phosphorylated extended conformation may therefore contribute to the increase in hNek6 Stokes radius. All hNek6 variants were submitted to SEC-MALS twice, using two different buffers (the same one used for SAXS and another one containing $600 \mathrm{mM} \mathrm{NaCl}$ in order to avoid any unspecific binding to the gel filtration column resin), and the same Stokes radii for each protein were obtained in both measurements. Figure 6 shows the results from SEC-MALS using the buffer containing $600 \mathrm{mM} \mathrm{NaCl}$, and Tables 2 and 3 show all the results obtained from both measurements.

Thermal denaturation shift assays were also performed for the five recombinant hNek6 variants described above. The results revealed a slightly higher stability of 
A

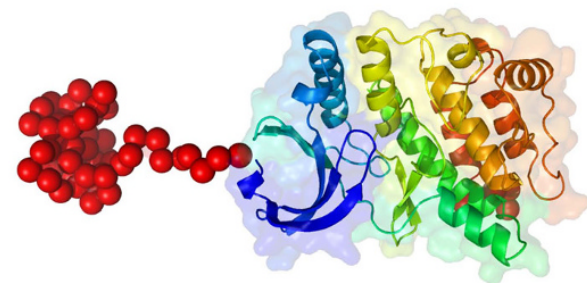

B

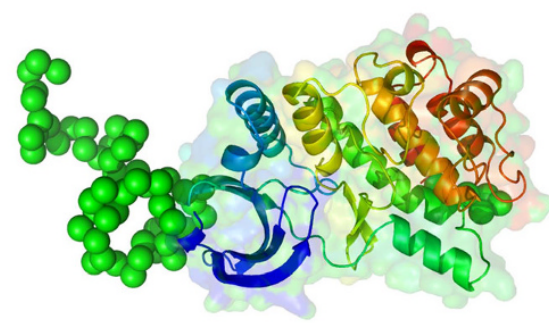

C

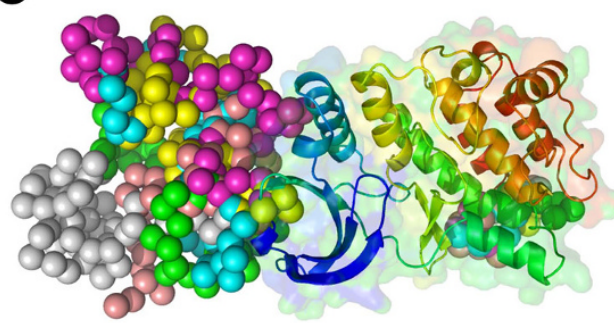

D
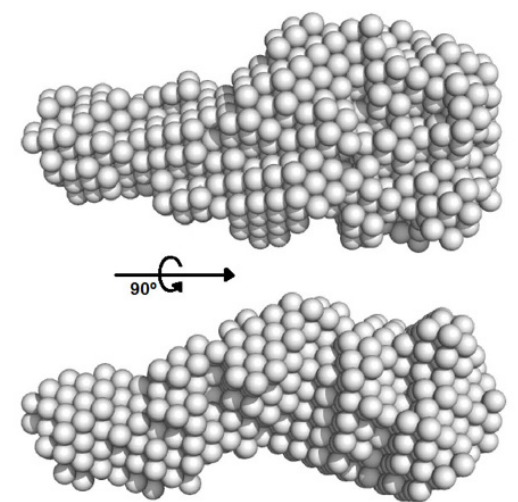

$20 \AA$
E
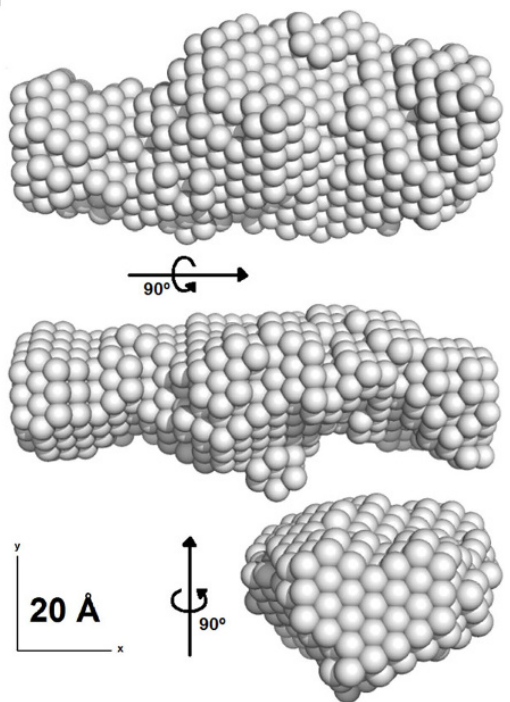

$\mathbf{F}$
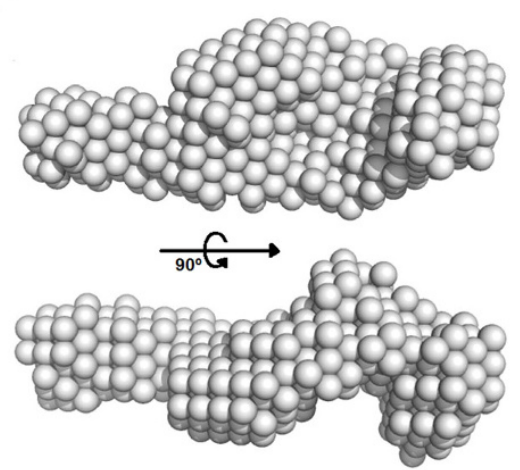

$20 \AA$

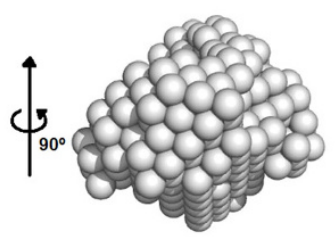

Figure 5 Low-resolution models of hNek6(S206A) obtained from the SAXS data using a combination of $a b$ initio calculations and rigid body modeling. (A and B) Two typical models selected from the set of 10 resulting models. (C) Superposition of all 10 models obtained in different and independent runs of the program BUNCH. (D) Three orthogonal views of the average molecular envelope of the 10 low resolution BUNCH models. (E) Three orthogonal views of the ab initio dummy atoms model. (F) Three orthogonal views of the ab initio dummy residues model. 
A

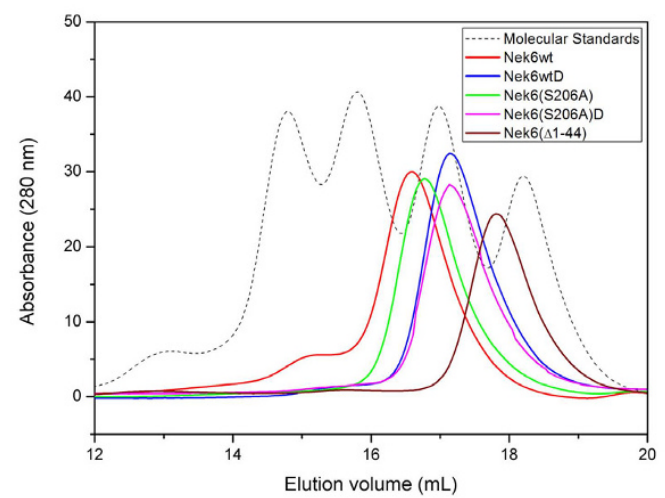

B

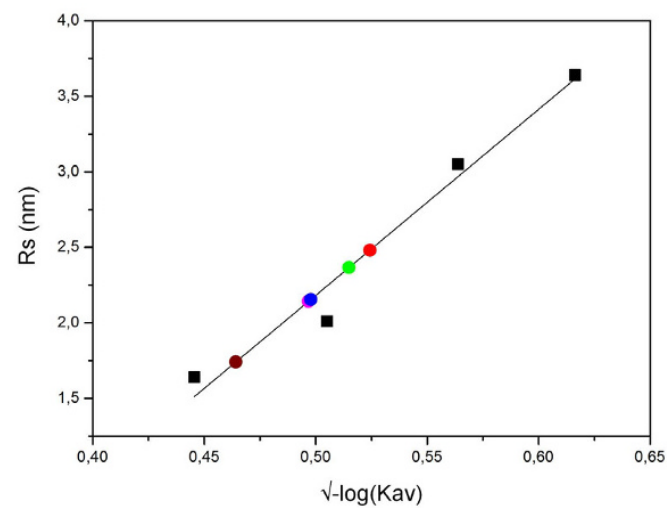

Figure 6 Analytical size-exclusion chromatography of recombinant hNek6 variants fused to a $6 x H i s$ tag. (A) Chromatographic profile of hNek6 variants (colored lines) and a mixture of standard proteins (dashed line). (B) Linear fit of known Stokes radii $\left(R_{\mathrm{s}}\right)$ as a function of the measured partition coefficient $\left(K_{\mathrm{av}}\right)$. The colored circles show the partition coefficient of hNek6 variants, and the black squares, the partition coefficients of the standards. The circles colors correspond to the same colors depicted in (A). The proteins were eluted in $50 \mathrm{mM} \mathrm{HEPES} \mathrm{pH} \mathrm{7.5,5} \mathrm{mM} \mathrm{sodium} \mathrm{phosphate,} 600 \mathrm{mM}$ $\mathrm{NaCl}, 5 \%$ glycerol, as homogeneous species at different elution volumes $\left(\mathrm{V}_{\mathrm{e}}\right)$ using an analytical Superdex 200 10/300 GL column. Conalbumin, ovalbumin, carbonic anhydrase and ribonuclease were used as Stokes radii standards. (wt: wild-type, D: dephosphorylated).

wild-type hNek6 compared to the activation loop mutant (Figure 7, Table 3). This may be explained by the fact that, in many kinases, like PKA, phosphorylation of the activation loop cause global stabilization of the active site [63], and molecular dynamics simulation of Cdk2 has demonstrated a decrease of B-factors throughout the molecule upon phosphorylation [64]. A model was proposed that dephosphorylation of the activation loop leads to mutual repulsion of the positive charges that were bound to the phosphate, which leads to the destabilization of the magnesium-binding loop, movement of the $\alpha \mathrm{C}$-helix out of the active site, disturbance of the hydrophobic spine, and loosening of the N-lobe, thereby providing an explanation of the protein kinase stabilization induced by phosphorylation [48]. This may therefore also reflect a higher stability for the wild-type hNek6 compared to its activation loop mutant in thermal melting measurements.

Table 2 Recombinant hNek6 Stokes radii $\left(R_{s}\right)$ determined by analytical size-exclusion chromatography

\begin{tabular}{lccc}
\hline Protein & $\boldsymbol{R}_{\mathbf{s}}(\mathbf{n m})$ & $\mathbf{V}_{\mathbf{e}}(\mathbf{m L})^{\mathbf{a}}$ & Apparent $\boldsymbol{R}_{\mathbf{s}}(\mathbf{n m})^{\mathbf{a}}$ \\
\hline Conalbumin & 3.6 & $14.9 \pm 0.1$ & $3.5 \pm 0.2$ \\
Ovalbumin & 3.0 & $15.8 \pm 0.1$ & $2.9 \pm 0.0$ \\
Carbonic Anhydrase & 2.0 & $16.9 \pm 0.1$ & $2.2 \pm 0.0$ \\
Ribonuclease & 1.6 & $18.2 \pm 0.0$ & $1.4 \pm 0.1$ \\
Nek6wt & & $16.4 \pm 0.3$ & $2.6 \pm 0.1$ \\
Nek6wtD & & $17.1 \pm 0.0$ & $2.1 \pm 0.0$ \\
Nek6(S206A) & & $16.7 \pm 0.2$ & $2.4 \pm 0.0$ \\
Nek6(S206A)D & & $17.1 \pm 0.0$ & $2.1 \pm 0.0$ \\
Nek6( $\triangle 1-44)$ & & $17.6 \pm 0.3$ & $1.8 \pm 0.1$ \\
\hline
\end{tabular}

${ }^{a}$ S.E. of two measurements at different buffers.

\section{Conclusions}

Our data presents the first low resolution 3D structure of hNek6 protein in solution. SAXS experiments show that hNek6 is a monomer of a mostly globular, though slightly elongated shape, which was also confirmed by analytical SEC-MALS experiments. These also showed that hNek6 conformation is dependent on its activation/phosphorylation status, a higher phosphorylation degree corresponding to a bigger Stokes radius. Thermal denaturation shift assays revealed a slightly higher stability of wild-type hNek6 compared to the activation loop mutant hNek6(S206A).

\section{Methods}

In silico sequence analysis

Human Nek6 and Nek7 amino acid sequences were used as queries in five different secondary structure prediction databases: PredictProtein/Prof [29], PSIPRED [30], SSpro [31], SOPMA [32] and GOR4 [33]. Comparison of their outputs resulted in a consensus of predicted secondary

Table 3 Recombinant hNek6 weight average molecular masses $\left(M_{\mathrm{w}}\right)$ determined by SEC-MALS and melting temperatures $\left(T_{\mathrm{m}}\right)$ during thermal shift denaturation

\begin{tabular}{lccc}
\hline Protein & Pred. $\boldsymbol{M}(\mathbf{k D a})^{\mathbf{a}}$ & $\boldsymbol{M}_{\mathbf{w}}(\mathbf{k D a})^{\mathbf{b}}$ & Apparent $\boldsymbol{T}_{\mathbf{m}}\left({ }^{\circ} \mathbf{C}\right)^{\mathbf{c}}$ \\
\hline Nek6wt & 37.7 & $38.4 \pm 0.6$ & $39.5 \pm 0.1$ \\
Nek6wtD & 37.7 & $37.8 \pm 2.2$ & $40.8 \pm 0.1$ \\
Nek6(S206A) & 37.7 & $38.1 \pm 2.1$ & $38.0 \pm 0.1$ \\
Nek6(S206A)D & 37.7 & $38.4 \pm 3.3$ & $36.8 \pm 0.3$ \\
Nek6(\1-44) & 33.2 & $33.3 \pm 1.6$ & $41.0 \pm 0.2$ \\
\hline
\end{tabular}

${ }^{a}$ Molecular masses predicted by ProtParam tool [60].

b S.E. of two measurements at different buffers.

c S.E. of three measurements. 


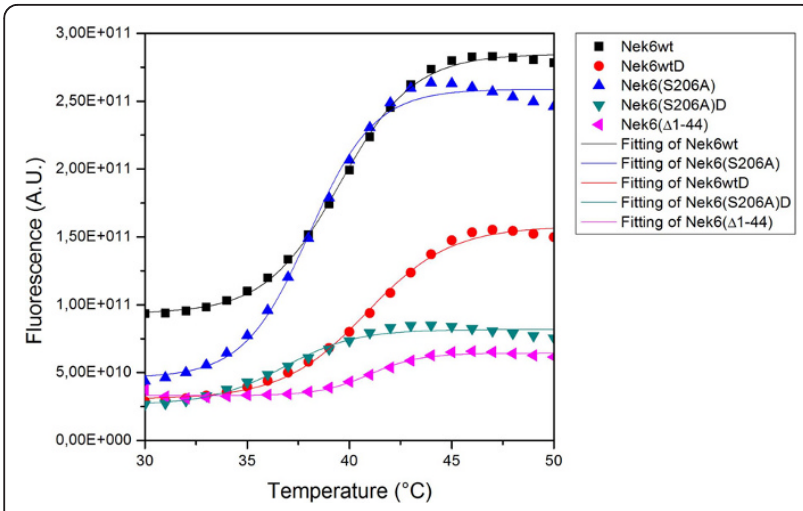

Figure 7 Thermal shift denaturation of recombinant hNek6 variants fused to a $6 \mathrm{xHis}$ tag. The graph shows representative thermal shift data (markers) and fitted curves (lines). Proteins were buffered in $10 \mathrm{mM}$ HEPES pH 7.5, $150 \mathrm{mM} \mathrm{NaCl}$ and assayed at a final concentration of $2.0 \mu \mathrm{M}$ in $25 \mu \mathrm{L}$ volume. SYPRO-Orange (Molecular Probes) was added as a fluorescence probe at a dilution of 1 in 1000. Temperature was raised with a step of $1^{\circ} \mathrm{C}$ per $1.0 \mathrm{~min}$ from $10^{\circ} \mathrm{C}$ to $85^{\circ} \mathrm{C}$ and fluorescence readings were taken at each interval. (wt: wild-type, D: dephosphorylated).

structure, where each amino acid was assigned a score ranging from 1 to 5 . Our Nek7 consensus of predicted secondary structure was compared to the authorapproved secondary structure in PDB (2WQM) as a measure to validate our analysis. We also performed disordered regions analysis for both protein sequences using nine different predictors: FoldIndex [34], GlobPlot Russell/Linding [35], PONDR VL-XT [36], DISpro [37], IUPred [38], DisEMBL Hot-loops, DisEMBL Remark465, DisEMBL Loops/coils [39], and VSL2B [40]. From this, a consensus of predicted disordered regions was generated with a consensus score ranging from 0 to 9 , where a score above 4 represents disorder. Additionally, NetPhosK [42] and NetPhos [43] databases were used to predict phosphorylation sites for human Nek6 and Nek7. The conserved glycine-rich sequence, the HRD and DLG motifs, the conserved residues $\mathrm{K}^{74}$ ( $\beta 3$ strand) and $E^{93}$ $(\alpha C$ helix), the putative nuclear export signal LGDLGL based on la Cour et al., 2004 [65], the putative WW domain binding motifs PY and pSP based on Ingham et al., 2005 [66], as long as the PPLP motif, experimentally described for hNek6 by Lee et al., 2007 [67], were also assigned to both protein sequences.

\section{Plasmid Constructions}

All plasmid constructions were developed accordingly to Meirelles et al., 2010 [41].

\section{Site-directed Mutagenesis}

The hNek6 activation loop mutation S206A was introduced by PCR-based mutagenesis accordingly to Meirelles et al., 2010 [41].

\section{Protein Expression and Purification}

Soluble full-length hNek6 wild-type - 6xHis-hNek6wt and mutant - 6xHis-hNek6(S206A) - or truncated hNek6 wild-type kinase domain - 6xHis-hNek6( $\Delta 1-44)$ fused to a $6 \mathrm{xHis}$ tag were expressed and purified accordingly to Meirelles et al., 2010 [41].

\section{Protein Dephosphorylation}

In order to obtain dephosphorylated wild-type and mutant hNek6, plasmids encoding either 6xHishNek6wt or 6 xHis-hNek6(S206A) and $\lambda$ phosphatase were transformed into E. coli BL21 (DE3/pRARE) cells that were induced and purified as described by Meirelles et al., 2010 [41]. Lambda phosphatase cloned into pCDF-Duet (Novagen) was kindly provided by Dr. Richard Bayliss (Section of Structural Biology, Institute of Cancer Research, London, UK).

\section{Circular dichroism}

Circular dichroism (CD) spectra were recorded in a JASCO model J-810 CD spectropolarimeter equipped with Peltier-type system PFD 425S. Data were collected from 260 to $200 \mathrm{~nm}$ at $4^{\circ} \mathrm{C}$ using a quartz cuvette of 1 $\mathrm{mm}$ pathlength. Thirty-two spectra of purified 6xHishNek6wt at $5.8 \mu \mathrm{M}$, in $50 \mathrm{mM}$ Phosphate buffer $\mathrm{pH} 7.5$, $300 \mathrm{mM} \mathrm{NaCl}$, were averaged and corrected from the baseline for buffer solvent contribution. Experimental data were analyzed using CDNN [45] and K2d [46] softwares.

\section{Comparative/Homology Molecular Modeling}

The comparative/homology molecular modeling and model validation were performed in a similar way to that described in Bodade et al., 2010 [68]. Briefly, several comparative/homology modeling tools were used: I-TASSER [69-71], Geno3D [72], 3D-JIGSAW [73-75], SWISS-MODEL [50] and MODELLER 9v8 [76]. The NCBI Basic Local Alignment Search Tool (BLAST, http://www.ncbi.nlm.nih.gov/BLAST/) was used to search the crystal structure of the closest homologue available in the Protein Data Bank (PDB, http://www. $\mathrm{rcsb} .0 \mathrm{rg} / \mathrm{pdb} /)$. The input was the amino acid sequence of hNek6(S206A). The NCBI results revealed that the structure of hNek7, deposited under the code 2WQM in the $\mathrm{PDB}$, was a very suitable template (identity score of $81 \%$ and E-value $3 \times 10^{-141}$ ). This structure was used as a single template for the modeling approach. The overall stereochemical quality of the models was assessed by PROCHECK software [77]. The quality of the models was also evaluated by PROSA $[51,52]$ and by the standard validation procedures included in the automated mode of the SWISSMODEL server [50]. 


\section{Small Angle X-Ray Scattering Analysis}

The sample was first inspected by dynamic light scattering (DLS) to test for its monodispersity and then ultracentrifuged at $200.000 \times \mathrm{g}$ for $40 \mathrm{~min}$ at $4^{\circ} \mathrm{C}$ to remove any possible aggregates. The SAXS experiments were performed at the D02A-SAXS2 beam line at the LNLS, and data treatment and analyses were done following standard procedures similar to those described in Trindade et al., 2009 [57]. Briefly, the measurements were performed at $4{ }^{\circ} \mathrm{C}$ and the sample-to-detector distance was $902 \mathrm{~mm}$, covering a scattering vector range of $0.015 \AA^{-1}<\mathrm{q}<0.25 \AA^{-1}$ (q is the magnitude of the $\mathbf{q}$-vector defined by $q=(4 \pi / \lambda) \sin \theta$ and $2 \theta$ is the scattering angle) using a wavelength of $\lambda=1.488 \AA$. The measurements were performed using two different protein concentrations in HEPES buffer (50 mM HEPES pH 7.5, $5 \mathrm{mM}$ sodium phosphate, $300 \mathrm{mM} \mathrm{NaCl}, 5 \%$ glycerol, $200 \mathrm{mM}$ imidazole): 0.5 and $1.0 \mathrm{mg} / \mathrm{mL}$. A $8 \mathrm{mg} / \mathrm{ml}$ BSA $(66 \mathrm{kDa})$ solution in the same sample buffer was used as a standard sample to estimate the molecular mass of 6xHis-hNek6(S206A) making use of the ratio of the extrapolated values of the intensity at the origin, $I(0)$ $[78,79]$. The radius of gyration $\left(R_{\mathrm{g}}\right)$ was calculated from the Guinier approximation (valid for $\mathrm{q} R_{\mathrm{g}}<1.3$ ) [80-82] and also from the pair distance distribution function, $p(\mathrm{r})$, which was obtained using the program GNOM [56]. The maximum dimension $\left(D_{\max }\right)$ of the molecule was obtained from the $p(r)$ function. The Kratky plot $\left(q^{2} \mathrm{I}(q)\right.$ vs. $\left.q\right)[81,82]$ was used to analyze the compactness of the protein conformation.

\section{Low resolution SAXS-based modeling}

The low resolution model of 6xHis-hNek6(S206A) was obtained from the SAXS data using a combination of $a b$ initio calculation and rigid body modeling methods. Taking advantage of the homology model obtained, we used the program BUNCH [61] to model the protein. No symmetry restraints were used in the calculation. We would like to mention that no unique solution can be obtained from these calculations. For this reason, 10 independent calculations were run for each sample data. The multiple solutions were analyzed and the reliability and stability of the set of models were estimated. A pairwise comparison and the normalized spatial discrepancy (NSD) evaluation was performed using the DAMAVER program suite [83] complemented by the SUPCOMB [84] routine. Analyzing the NSD values (which describe the dissimilarity between pairs of models of the several calculations), the models with common features led to the selection of a representative, low resolution conformation for hNek6(S206A) protein. Models were displayed by the PyMOL program [85].

For comparison purposes, two other low resolution models were also obtained by using two different ab initio approaches: the dummy atoms method implemented in the program DAMMIN [86] and the dummy residues method implemented in GASBOR [87]. The procedures were similar to those described in Trindade et al. [57].

\section{SEC-MALS Analysis}

We used Analytical Size-Exclusion Chromatography coupled to Multi-Angle Light $\underline{\text { Scattering }}$ (SEC-MALS) to estimate the hydrodynamic or Stokes radii $\left(R_{\mathrm{s}}\right)$ of recombinant hNek6wt, hNek6(S206A), hNek6( $\Delta 1-44)$ and dephosphorylated hNek6wt and hNek6(S206A), all fused to a $6 x$ His tag. SEC was performed with an analytical Superdex 200 10/300 GL column using an ÄKTA FPLC system (GE Healthcare) equilibrated with two column volumes of $50 \mathrm{mM}$ HEPES pH 7.5, $5 \mathrm{mM}$ sodium phosphate, $600 \mathrm{mM} \mathrm{NaCl}, 5 \%$ glycerol, at a flow rate of $0.5 \mathrm{ml} / \mathrm{min}$, at $20^{\circ} \mathrm{C}$. Recombinant hNek6 variants at concentrations ranging from 0.2 to $0.7 \mathrm{mg} / \mathrm{ml}$ and a mixture of standard proteins with known Stokes radii (conalbumin: $3.64 \mathrm{~nm}, 3.2 \mathrm{mg} / \mathrm{ml}$; ovalbumin: $3.05 \mathrm{~nm}$, $4.2 \mathrm{mg} / \mathrm{ml}$; carbonic anhydrase: $2.30 \mathrm{~nm}, 3.0 \mathrm{mg} / \mathrm{ml}$; and ribonuclease: $1.64 \mathrm{~nm}, 3.4 \mathrm{mg} / \mathrm{ml}$ ) (Sigma) were loaded onto the column and their elution profiles were monitored by absorbance at $280 \mathrm{~nm}$. The Stokes radius of each hNek6 variant was estimated by a linear fit of the Stokes radii of the standard proteins versus the partition coefficient $K_{\mathrm{av}}[88,89]$ as described by the equation: $K_{\mathrm{av}}$ $=V_{\mathrm{e}}-V_{\mathrm{o}} / V_{\mathrm{t}}-V_{\mathrm{o}}$, where $V_{\mathrm{e}}$ is the elution volume of the protein, $V_{\mathrm{o}}$ the void volume and $V_{\mathrm{t}}$ is the total volume of the column. The SEC was also coupled to a DAWN TREOSTM MALS instrument (Wyatt Technology). The on-line measurement of the intensity of the Rayleigh scattering as a function of the angle of the eluting peaks in SEC was used to determine the weight average molecular masses $\left(M_{\mathrm{w}}\right)$ of the eluted proteins [90], using the ASTRATM (Wyatt Technologies) software. SEC-MALS measurements were performed using two different buffers: the first one described above for SEC and a second one also used in SAXS experiments (50 mM HEPES pH 7.5, $5 \mathrm{mM}$ sodium phosphate, $300 \mathrm{mM} \mathrm{NaCl}, 5 \%$ glycerol, $200 \mathrm{mM}$ imidazole). The chromatographic profile of the recombinant hNek6 variants were the same in both measurements and the mean and standard errors of their $M_{\mathrm{w}}$ and $M_{\mathrm{n}}$ were calculated.

\section{Thermal Shift Assays}

Thermal shift assays were performed based on a protocol devised by the Structural Genomics Consortium [91] using a real time PCR machine 7300 (Applied Biosystems). Proteins were buffered in $10 \mathrm{mM}$ HEPES $\mathrm{pH} 7.5$, $150 \mathrm{mM} \mathrm{NaCl}$ and assayed at a final concentration of $2.0 \mu \mathrm{M}$ in $25 \mu \mathrm{L}$ volume. SYPRO-Orange (Molecular Probes) was added as a fluorescence probe at a dilution 
of 1 in 1000. The emission filter for the SYPRO-Orange dye was set to $580 \mathrm{~nm}$. Temperature was raised with a step of $1^{\circ} \mathrm{C}$ per $1.0 \mathrm{~min}$ from $10^{\circ} \mathrm{C}$ to $85^{\circ} \mathrm{C}$ and fluorescence readings were taken at each interval. OriginPro 8 software was used to fit data to the Boltzmann equation, $\mathrm{y}=\mathrm{LL}+(\mathrm{UL}-\mathrm{LL}) / 1+\exp \left(\left(T_{\mathrm{m}}-\mathrm{x}\right) / \mathrm{a}\right)$, where LL and UL are the slopes of the native and denatured baselines, $T_{\mathrm{m}}$ is the apparent melting temperature and a describes the slope of the denaturation. $T_{\mathrm{m}}$ values were calculated by determination of the maximum of the first derivative.

\section{Additional material}

Additional file 1: Supplemental Figures S1 and S2, PROCHECK and PROSA analysis results of the validation procedures of the hNek6 (S206A) homology/comparative model and Analytical SEC-MALS of the five recombinant protein variants of Nek6. Figure S1: PROCHECK and PROSA analysis results of the validation procedures of the hNek6 (S206A) homology/comparative model. (A) Ramachandran Plot calculated using the program PROCHECK. (B) Plot of the residue score showing the local model quality by plotting energies as a function of the residue sequence position using PROSA. In general, positive values correspond to problematic or erroneous parts of the structure. Here, the plots were smoothed by calculation the average energy over 10- and 40-residues. This average is needed because of the large fluctuation in a plot of single residue energies. (C) The Z-score indicated overall model quality using PROSA. The Z-score of the hNek6(S206A) model was -7.14 (black point). The plot contains the Z-scores of all experimentally determined protein chains in the current PDB. The structure determined by $X$-ray and NMR are distinguished by different colors. Figure S2: Analytical SEC-MALS of recombinant (A) hNek6wt, (B) hNek6wtD, (C) hNek6(S206A), (D) hNek6 (S206A)D and (E) hNek6( $\triangle 1-44)$. The Mw determined by MALS correspond to a monomer in all five cases.

\section{Acknowledgements}

Financially supported by: Fundação de Amparo à Pesquisa do Estado São Paulo, the Conselho Nacional de Pesquisa e Desenvolvimento and the LNLS. We thank Maria Eugenia R. Camargo for technical assistance, Rodrigo Martinez for the technical support at the SAXS2 beamline, and Dr. Richard Bayliss (Section of Structural Biology, Institute of Cancer Research, London, UK) for providing the pCDF-Duet lambda phosphatase construct.

\section{Author details}

'Laboratório Nacional de Biociências, Centro Nacional de Pesquisa em Energia e Materiais, Campinas, SP, Brazil. ${ }^{2}$ Departamento de BioquímicaPrograma de Pós-graduação em Biologia Funcional e Molecular, Instituto de Biologia, Universidade Estadual de Campinas, $13083-970$ Campinas, SP, Brazil. ${ }^{3}$ Instituto de Química, Universidade Estadual de Campinas, Campinas, SP, Brazil. ${ }^{4}$ Laboratório Nacional de Luz Síncrotron, Centro Nacional de Pesquisa em Energia e Materiais, Campinas, SP, Brazil. ${ }^{5}$ Instituto de Física "Gleb Wataghin", Universidade Estadual de Campinas, Campinas, SP, Brazil.

\section{Authors' contributions}

GVM and JK conceived and designed the experiments, analyzed the data and wrote the manuscript. GVM performed the experiments. JCS performed comparative molecular modeling and SAXS experiments and interpreted them together with ICLT. YAM helped in SEC-MALS and CD experiments which were analyzed together with CHIR. JK supervised the project. All authors read and approved the final version of the manuscript.

Received: 10 September 2010 Accepted: 14 February 2011 Published: 14 February 2011
References

1. Barr FA, Sillje HH, Nigg EA: Polo-like kinases and the orchestration of cell division. Nat Rev Mol Cell Biol 2004, 5:429-440.

2. Carmena M, Earnshaw WC: The cellular geography of aurora kinases. Nat Rev Mol Cell Biol 2003, 4:842-854.

3. Nigg EA: Mitotic kinases as regulators of cell division and its checkpoints. Nat Rev Mol Cell Biol 2001, 2:21-32.

4. O'Regan L, Blot J, Fry AM: Mitotic regulation by NIMA-related kinases. Cell Div 2007, 2:25.

5. Fry AM: The Nek2 protein kinase: a novel regulator of centrosome structure. Oncogene 2002, 21(40):6184-94.

6. Quarmby LM, Mahjoub MR: Caught Nek-ing: cilia and centrioles. J Cell Sci 2005, 118:5161-5169.

7. White MC, Quarmby LM: The NIMA-family kinase, Nek1 affects the stability of centrosomes and ciliogenesis. BMC Cell Biol 2008, 9:29.

8. Lanza DC, Meirelles GV, Alborghetti MR, Abrile CH, Lenz G, Kobarg J: FEZ1 interacts with CLASP2 and NEK1 through coiled-coil regions and their cellular colocalization suggests centrosomal functions and regulation by PKC. Mol Cell Biochem 2010, 338(1-2):35-45.

9. O'Regan L, Fry AM: The Nek6 and Nek7 protein kinases are required for robust mitotic spindle formation and cytokinesis. Mol Cell Biol 2009, 29:3975-3990.

10. Yissachar N, Salem H, Tennenbaum T, Motro B: Nek7 kinase is enriched at the centrosome, and is required for proper spindle assembly and mitotic progression. FEBS Lett 2006, 580(27):6489-95.

11. Roig J, Groen A, Caldwell J, Avruch J: Active Nercc1 protein kinase concentrates at centrosomes early in mitosis and is necessary for proper spindle assembly. Mol Biol Cell 2005, 16(10):4827-40.

12. Roig J, Mikhailov A, Belham C, Avruch J: Nercc1, a mammalian NIMAfamily kinase, binds the Ran GTPase and regulates mitotic progression. Genes Dev 2002, 16:1640-1658.

13. Belham C, Roig J, Caldwell JA, Aoyama Y, Kemp BE, Comb M, Avruch J: A mitotic cascade of NIMA family kinases. Nercc1/Nek9 activates the Nek6 and Nek7 kinases. J Biol Chem 2003, 278:34897-34909.

14. Upadhya P, Birkenmeier EH, Birkenmeier CS, Barker JE: Mutations in a NIMA-related kinase gene, Nek1, cause pleiotropic effects including a progressive polycystic kidney disease in mice. Proc Natl Acad Sci 2000, 97(1):217-21.

15. Liu S, Lu W, Obara T, Kuida S, Lehoczky J, et al: A defect in a novel Nekfamily kinase causes cystic kidney disease in the mouse and in zebrafish. Development 2002, 129(24):5839-46.

16. Surpili MJ, Delben TM, Kobarg J: Identification of proteins that interact with the central coiled-coil region of the human protein kinase NEK1. Biochemistry 2003, 42:15369-15376.

17. Tsunoda N, Kokuryo T, Oda K, Senga T, Yokoyama Y, et al: Nek2 as a novel molecular target for the treatment of breast carcinoma. Cancer Sci 2009, 100(1):111-6.

18. McHale K, Tomaszewski JE, Puthiyaveettil R, Livolsi VA, Clevenger CV: Altered expression of prolactin receptor-associated signaling proteins in human breast carcinoma. Mod Pathol 2008, 21(5):565-71.

19. Bowers AJ, Boylan JF: Nek8, a NIMA family kinase member, is overexpressed in primary human breast tumors. Gene 2004, 328:135-42.

20. Ahmed S, Thomas G, Ghoussaini M, Healey CS, Humphreys MK, et al: Newly discovered breast cancer susceptibility loci on 3p24 and 17q23.2. Nat Genet 2009, 41(5):585-90.

21. Chen J, Li L, Zhang Y, Yang H, Wei Y, et al: Interaction of Pin1 with Nek6 and characterization of their expression correlation in Chinese hepatocellular carcinoma patients. Biochem Biophys Res Commun 2006, 341(4):1059-65.

22. Capra M, Nuciforo PG, Confalonieri S, Quarto M, Bianchi M, et al: Frequent alterations in the expression of serine/threonine kinases in human cancers. Cancer Res 2006, 66(16):8147-54.

23. Takeno A, Takemasa I, Doki Y, Yamasaki M, Miyata H, et al: Integrative approach for differentially overexpressed genes in gastric cancer by combining large-scale gene expression profiling and network analysis. $\mathrm{Br}$ J Cancer 2008, 99(8):1307-15.

24. Nassirpour R, Shao L, Flanagan P, Abrams T, Jallal B, Smeal T, Yin MJ: Nek6 Mediates Human Cancer Cell Transformation and Is a Potential Cancer Therapeutic Target. Mol Cancer Res 2010, 8(5):717-28. 
25. Minoguchi S, Minoguchi M, Yoshimura A: Differential control of the NIMArelated kinases, Nek6 and Nek7, by serum stimulation. Biochem Biophys Res Commun 2003, 301:899-906.

26. Rellos P, Ivins FJ, Baxter JE, Pike A, Nott TJ, Parkinson DM, Das S, Howell S, Fedorov O, Shen QY, Fry AM, Knapp S, Smerdon SJ: Structure and regulation of the human Nek2 centrosomal kinase. J Biol Chem 2007, 282(9):6833-42.

27. Westwood I, Cheary DM, Baxter JE, Richards MW, van Montfort RL, Fry AM, Bayliss R: Insights into the conformational variability and regulation of human Nek2 kinase. J Mol Biol 2009, 386(2):476-85.

28. Richards MW, O'Regan L, Mas-Droux C, Blot JM, Cheung J, Hoelder S, Fry AM, Bayliss R: An autoinhibitory tyrosine motif in the cell-cycleregulated Nek7 kinase is released through binding of Nek9. Mol Cell 2009, 36(4):560-70.

29. Rost B, Yachdav G, Liu J: The PredictProtein server. Nucleic Acids Res 2004, 32:W321-W326.

30. Bryson K, McGuffin LJ, Marsden RL, Ward JJ, Sodhi JS, Jones DT: Protein structure prediction servers at University College London. Nucleic Acids Res 2005, 33:W36-W38.

31. Cheng J, Randall AZ, Sweredoski MJ, Baldi P: SCRATCH: a protein structure and structural feature prediction server. Nucleic Acids Res 2005, 33 W72-W76.

32. Geourjon C, Deleage G: SOPMA: significant improvements in protein secondary structure prediction by consensus prediction from multiple alignments. Comput Appl Biosci 1995, 11:681-684.

33. Garnier J, Gibrat J-F, Robson B: GOR secondary structure prediction method version IV. Met Enzymol 1996, 266:540-553.

34. Prilusky J, Felder CE, Zeev-Ben-Mordehai T, Rydberg EH, Man O, Beckmann JS, Silman I, Sussman JL: FoldIndex: a simple tool to predict whether a given protein sequence is intrinsically unfolded. Bioinformatics 2005, 21(16):3435-8.

35. Linding R, Russell RB, Neduva V, Gibson TJ: GlobPlot: Exploring protein sequences for globularity and disorder. Nucleic Acids Res 2003, 31(13):3701-8.

36. Romero P, Obradovic Z, Li X, Garner EC, Brown CJ, Dunker AK: Sequence complexity of disordered protein. Proteins 2001, 42(1):38-48.

37. Cheng J, Sweredoski M, Baldi P: Accurate Prediction of Protein Disordered Regions by Mining Protein Structure Data. Data Mining and Knowledge Discovery 2005, 11(3):213-222.

38. Dosztanyi Z, Csizmok V, Tompa P, Simon I: IUPred: web server for the prediction of intrinsically unstructured regions of proteins based on estimated energy content. Bioinformatics 2005, 21(16):3433-4.

39. Linding R, Jensen LJ, Diella F, Bork P, Gibson TJ, Russell RB: Protein disorder prediction: implications for structural proteomics. Structure 2003, 11(11):1453-9.

40. Obradovic Z, Peng K, Vucetic S, Radivojac P, Dunker AK: Exploiting heterogeneous sequence properties improves prediction of protein disorder. Proteins 2005, 61(7):176-82.

41. Meirelles GV, Lanza DCF, Silva JC, Bernachi JS, Leme AFP, Kobarg J: Characterization of hNek6 Interactome Reveals an Important Role for Its Short N-Terminal Domain and Colocalization with Proteins at the Centrosome. J Proteome Res 2010, 9(12):6298-316.

42. Blom N, Sicheritz-Ponten T, Gupta R, Gammeltoft S, Brunak S: Protein disorder prediction: implications for structural proteomics. Proteomics 2004, 4(6):1633-49.

43. Blom N, Gammeltoft S, Brunak S: Sequence- and structure-based prediction of eukaryotic protein phosphorylation sites. J Mol Biol 1999, 294(5):1351-1362.

44. Chen YH, Yang JT, Martinez HM: Determination of the secondary structures of proteins by circular dichroism and optical rotatory dispersion. Biochemistry 1972, 11:4120-4131.

45. Bohm G, Muhr R, Jaenicke R: Quantitative analyses of protein far UV circular dichroism spectra by neural networks. Protein Engineering 1992, 5:191-195

46. Andrade MA, Chacón P, Merelo JJ, Morán F: Evaluation of secondary structure of proteins from UV circular dichroism using an unsupervised learning neural network. Prot Eng 1993, 6:383-390.

47. Correa DHA, Ramos CHI: The use of circular dichroism spectroscopy to study protein folding, form and function. African J Biochem Res 2009, 3(5):164-173.
48. Kornev AP, Haste NM, Taylor SS, Eyck LF: Surface comparison of active and inactive protein kinases identifies a conserved activation mechanism. Proc Natl Acad Sci USA 2006, 103(47):17783-8.

49. Huse M, Kuriyan J: The conformational plasticity of protein kinases. Cell 2002, 109(3):275-82.

50. Schwede T, Kopp J, Guex N, Peitsch MC: SWISS-MODEL: An automated protein homology-modeling server. Nucleic Acids Res 2003, 31(13):3381-3385.

51. Wiederstein M, Sippl MJ: ProSA-web: interactive web service for the recognition of errors in three-dimensional structures of proteins. Nucleic Acids Res 2007, 35:W407-10.

52. Sippl MJ: Recognition of Errors in Three-Dimensional Structures of Proteins. Proteins 1993, 17:355-362.

53. Zhang X, Gureasko J, Shen K, Cole PA, Kuriyan J: An allosteric mechanism for activation of the kinase domain of epidermal growth factor receptor. Cell 2006, 125:1137-1149.

54. Sicheri F, Kuriyan J: Structures of Src-family tyrosine kinases. Curr Op Struct Biol 1997, 7:777-785.

55. Bressan GC, Silva JC, Borges JC, Dos Passos DO, Ramos CH, Torriani IL, Kobarg J: Human regulatory protein $\mathrm{Ki}-1 / 57$ has characteristics of an intrinsically unstructured protein. J Proteome Res 2008, 7(10):4465-74.

56. Lanza DC, Silva JC, Assmann EM, Quaresma AJ, Bressan GC, Torriani IL, Kobarg J: Human FEZ1 has characteristics of a natively unfolded protein and dimerizes in solution. Proteins 2009, 74:104-21.

57. Trindade DM, Silva JC, Navarro MS, Torriani IC, Kobarg J: Low-resolution structural studies of human Stanniocalcin-1. BMC Struct Biol 2009, 9:57.

58. Gonçalves KA, Borges JC, Silva JC, Papa PF, Bressan GC, Torriani IL, Kobarg J: Solution structure of the human signaling protein RACK1. BMC Struct Biol 2010, 10:15

59. Svergun DI: Determination of the regularization parameter in indirecttransform methods using perceptual criteria. J App/ Cryst 1992, 25:495-503.

60. Gasteiger E, Gattiker A, Hoogland C, Ivanyi I, Appel RD, Bairoch A: ExPASy: The proteomics server for in-depth protein knowledge and analysis. Nucleic Acids Res 2003, 31:3784-3788.

61. Volkov W, Svergun DI: Uniqueness of ab initio shape determination in small-angle scattering. J App/ Crystallogr 2003, 36:860-864.

62. Rizos AK, Tsikalas I, Morikis D, Galanakis P, Spyroulias GA, Krambovitis E: Characterization of the interaction between peptides derived from the gp120/V3 domain of HIV-1 and the amino terminal of the chemokine receptor CCR5 by NMR spectroscopy and light scattering. J Non-Cryst Solids 2006, 352:4451-4458.

63. Iyer GH, Garrod S, Woods VL Jr, Taylor SS: Catalytic independent functions of a protein kinase as revealed by a kinase-dead mutant: study of the Lys72His mutant of cAMP-dependent kinase. J Mol Biol 2005, 351(5):1110-22.

64. Barrett $\mathrm{CP}$, Noble ME: Molecular motions of human cyclin-dependent kinase 2. J Biol Chem 2005, 280(14):13993-4005.

65. Ia Cour T, Kiemer L, Mølgaard A, Gupta R, Skriver K, Brunak S: Analysis and prediction of leucine-rich nuclear export signals. Protein Eng Des Sel 2004, 17(6):527-36.

66. Ingham RJ, Colwill K, Howard C, Dettwiler S, Lim CS, Yu J, Hersi K, Raaijmakers J, Gish G, Mbamalu G, Taylor L, Yeung B, Vassilovski G, Amin M, Chen F, Matskova L, Winberg G, Ernberg I, Linding R, O'donnell P, Starostine A, Keller W, Metalnikov P, Stark C, Pawson T: WW domains provide a platform for the assembly of multiprotein networks. Mol Cell Biol 2005, 25(16):7092-106.

67. Lee EJ, Hyun SH, Chun J, Kang SS: Human NIMA-related kinase 6 is one of the Fe65 WW domain binding proteins. Biochem Biophys Res Commun 2007, 358(3):783-8.

68. Bodade RG, Beedkar SD, Manwar AV, Khobragade CN: Homology modeling and docking study of xanthine oxidase of Arthrobacter sp. XL26. Int J Biol Macromol 2010, 47(2):298-303.

69. Roy A, Kucukural A, Zhang Y: I-TASSER: a unified platform for automated protein structure and function prediction. Nat Protoc 2003, 5(4):725-38.

70. Zhang Y: I-TASSER: Fully automated protein structure prediction in CASP8. Proteins 2009, 7759:100-113.

71. Zhang Y: I-TASSER server for protein 3D structure prediction. BMC Bioinformatics 2008, 9:40. 
72. Combet C, Jambon M, Deléage G, Geourjon C: Geno3D: Automatic comparative molecular modeling of protein. Bioinformatics 2002, 18:213-214

73. Bates PA, Kelley LA, MacCallum RM, Sternberg MJE: Enhancement of Protein Modeling by Human Intervention in Applying the Automatic Programs 3D-JIGSAW and 3D-PSSM. Proteins 2001, S5:39-46.

74. Bates PA, Sternberg MJE: Model Building by Comparison at CASP3: Using Expert Knowledge and Computer Automation. Proteins 1999, S3:47-54.

75. Contreras-Moreira B, Bates PA: Domain Fishing: a first step in protein comparative modeling. Bioinformatics 1999, 18:1141-1142.

76. Sali A, Blundell TL: Comparative protein modeling by satisfaction of spatial restraints. J Mol Biol 1993, 234:779-815.

77. Laskowski RA, MacArthur MW, Moss DS, Thornton JM: Procheck - a program to check the stereochemical quality of protein structures. J Appl Crystallogr 1993, 26:283-291.

78. Orthaber D, Bergmann A, Glatter O: SAXS experiments on absolute scale with Kratky systems using water as a secondary standard. J Appl Crystallogr 2000, 33:218-255.

79. Mylonas $E$, Svergun Dl: Accuracy of molecular mass determination of proteins in solution by small-angle X-ray scattering. J App/ Crystallogr 2001, 40:245-249.

80. Guinier A, Fournet G: Small angle scattering of X-rays New York, John Wiley and Sons, Inc; 1955.

81. Glatter O, Kratky O: Small angle X-ray scattering New York, Academic Press; 1982.

82. Feigin LA, Svergun DI: Structure analysis by small angle X-ray and neutron scattering New York, Plenum Press; 1987.

83. Petoukhov MV, Svergun Dl: Global rigid body modeling of macromolecular complexes against small-angle scattering data. Biophys $\lrcorner$ 2005, 89:1237-1250.

84. Kozin PV, Svergun DI: Automated matching of high- and low-resolution structural models. I Appl Crystallogr 2001, 34:33-41.

85. DeLano WL: The PyMOL molecular graphics system. 2002.

86. Svergun DI: Restoring low resolution structure of biological macromolecules from solution scattering using simulated annealing. Biophys J 1999, 76:2879-2886

87. Svergun DI, Petoukhov MV, Koch MH: Determination of domain structure of proteins from X-ray solution scattering. Biophys J 2001, 80:2946-2953.

88. Le Maire M, Rivas E, Moller JV: Use of gel chromatography for determination of size and molecular weight of proteins: Further caution. Analyt Biochem 1980, 106:12-21.

89. Siegel LM, Monty KJ: Determination of molecular weights and frictional ratios of proteins in impure systems by use of gel filtration and density gradient centrifugation. Application to crude preparations of sulfite and hydroxylamine reductases. Biochim Biophys Acta 1966, 112:346-362.

90. Trathnigg B: Determination of MWD and Chemical Composition of Polymers by Chromatographic Techniques. Prog Polym Sci 1995, 20:615-650.

91. Niesen $F H$, Berglund $H$, Vedadi M: The use of differential scanning fluorimetry to detect ligand interactions that promote protein stability. Nat Protoc 2007, 2(9):2212-21

doi:10.1186/1472-6807-11-12

Cite this article as: Meirelles et al: Human Nek6 is a monomeric mostly globular kinase with an unfolded short $\mathrm{N}$-terminal domain. BMC Structural Biology 2011 11:12.

\section{Submit your next manuscript to BioMed Central and take full advantage of:}

- Convenient online submission

- Thorough peer review

- No space constraints or color figure charges

- Immediate publication on acceptance

- Inclusion in PubMed, CAS, Scopus and Google Scholar

- Research which is freely available for redistribution

Submit your manuscript at www.biomedcentral.com/submit
Biomed Central 